\title{
Strain-Related Differences on Response of Liver and Kidney Antioxidant Defense System in Two Rat Strains Following Diazinon Exposure
}

\author{
Maryam Salehi, ${ }^{1}$ Mahvash Jafari, ${ }^{2,}$ Alireza Asgari, ${ }^{3}$ Mohammad Salimian, ${ }^{4}$ Maryam Abbasnezhad, ${ }^{5}$ \\ Reza Haji Hosseini, ${ }^{5}$ and Mansoureh Hajigholamali ${ }^{5}$

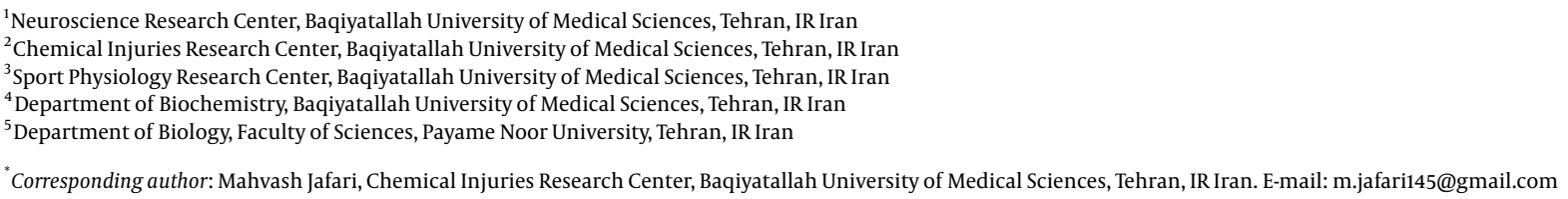

Received 2015 March 19; Accepted 2015 July 12.

\begin{abstract}
Background: Diazinon (DZN) is one of the most organophosphates that widely used in agriculture and ectoparasiticide formulations. Its extensive use as an effective pesticide was associated with the environmental deleterious effects on biological systems. Objectives: The aim of this study was to investigate the potency of DZN to affect serum biochemical parameters and the antioxidant defense system in the liver and kidney of two rat strains.

Materials and Methods: In this experimental study, 30 female Wistar and 30 female Norway rats were randomly divided into control and DZN groups. DZN group was divided into four subgroups: 25, 50, 100 and $200 \mathrm{mg} / \mathrm{kg}$ of DZN administered groups by i.p. injection. The parameters were evaluated after 24 hours.

Results: At higher doses of DZN, superoxide dismutase, catalase, glutathione S-transferase and lactate dehydrogenase activities and glutathione (GSH) and malondialdehyde levels in liver and kidney of Wistar rats were higher than Norway rats. At these concentrations, DZN increased some serum biochemical indices such as liver enzymes activities and levels of urea, uric acid and creatinine in Wistar rat.

Conclusions: DZN at higher doses alters the oxidant-antioxidant balance in liver and kidney of both rat strains and induces oxidative stress, which is associated with a depletion of GSH and increased lipid peroxidation. However, Wistar rats are found to be more sensitive to the toxicity of DZN compared to Norway rats. In addition, the effect of DZN on liver antioxidant system was more than kidney.
\end{abstract}

Keywords: Diazinon, Antioxidant System, Liver, Kidney, Rat Starins

\section{Background}

Organophosphate (OP) compounds are used in agriculture as pesticides, insecticides and acaricides, in military technology as chemical warfare agents (nerve agents) and in industry as antioxidants. Despite the apparent benefits of these uses, pesticides are potentially toxic substances released into the environment in large amounts with the potential to cause adverse effects on human and wildlife populations. There are 3 million cases of severe poisoning and 220,000 deaths in every year. OPs have been reported as the third most common cause of poisoning and the principal cause of poisoning-related mortality in Iran $[1,2]$.

Diazinon (DZN) is one of the important OPs that widely used in agriculture to control insects and veterinary medicine to control ectoparasites. It readily absorbed and mainly eliminated by the kidney. In human liver, DZN is metabolized to diazoxon through oxidative desulfuration within a few hours, which is substantially more toxic $[3,4]$.

The major mechanism of acute toxic action of OPs is the inhibition of acetylcholinesterase, which leads to accumulation of acetylcholine and failure of the central nervous system and death [5]. In addition, several studies have shown that OPs induce the generation of reactive oxygen species (ROS), depletion of endogenous antioxidants and increase of lipid peroxidation in humans and animals, all of which can lead to oxidative stress and finally cell death $[1,4,6,7]$. Handy et al. [8] observed pathological changes in spleen, thymus and blood cells following oral administration of $300 \mathrm{mg} / \mathrm{kg}$ DZN to mice. Tissue differences in the oxidative stress responses and antioxidants are also reported in various fish species [9]. 
Due to the variation of substitutions in chemical structure of OPs and their various effects on different tissues and strains [10], further studies are necessary to understand the mechanism of action of these compounds. To the best of our knowledge, there are only few studies on the dosedependent effect of DZN on antioxidant defense system in various organs of different rat strains after intraperitoneal (i.p.) injection [11].

\section{Objectives}

The aim of the present study was to evaluate the oxidative effects of DZN on biochemical parameters in serum and oxidative stress biomarkers such as glutathione (GSH) and superoxide dismutase (SOD), catalase (CAT), glutathione S-transferase (GST) and malondialdehyde (MDA) as an important index of lipid peroxidation in liver and kidney of female Wistar and Norway rats.

\section{Materials and Methods}

\subsection{Chemicals}

In this experimental study, all other chemicals used were of extra pure grad and obtained from Sigma and Merck. DZN, purity 99\%, was obtained from Supelco Company (USA) and dissolved in corn oil at a stock concentration of $800 \mathrm{mg} / \mathrm{mL}$, immediately before use.

\subsection{Animals}

Thirty female Wistar rat from Baqiyatallah University of Medical Sciences (Tehran, Iran) and 30 female brown Norway rat from Sewage system of Tehran (150 - $200 \mathrm{~g}$ body weight and 4 - 6 weeks old) were obtained. The rats were housed three to a cage and acclimated for at least 2 weeks prior to experimental use. All the animals were fed a standard rat chow and water ad libitum and kept in a temperature-controlled environment $\left(20^{\circ} \mathrm{C}-22^{\circ} \mathrm{C}\right)$ with an alternating cycle of 12 -hour light and dark. The ethics committee of the Baqiyatallah University of Medical Sciences approved the experimental protocol and all efforts were made to minimize the animal suffering.

\subsection{Animal Treatment With DZN}

The rats were randomly divided into control and DZNtreated groups. Control group received only corn oil. DZNtreated group were divided into four equal subgroups that were treated with 25, 50,100 and $200 \mathrm{mg} / \mathrm{kg}$ of DZN by i.p. injection. The doses used were in accordance with those in previous works [12]. All rats were weighed at the beginning and at the end of the study.

\subsection{Serum and Tissue Preparation}

Six rats in each group were anesthetized with diethyl ether 24 hours $[12,13]$ after DZN administration. Blood samples were taken by cardiac puncture and allowed to stand for 30 minutes at room temperature to clot before being centrifuged at 3,000 $\times \mathrm{g}$ for 15 minutes. Serum were obtained by centrifugation and stored at $-20^{\circ} \mathrm{C}$. Liver and kidney were quickly removed, washed in ice-cold phosphate buffer saline (PBS). Washed tissues were immediately immersed in liquid nitrogen and stored at $-70^{\circ} \mathrm{C}$ until biochemical analysis.

On the day of use, frozen tissue samples were quickly weighed and homogenized 1: 10 in ice-cold PBS. The homogenates were then centrifuged at $16,000 \times \mathrm{g}$ for $15 \mathrm{~min}$ utes at $4^{\circ} \mathrm{C}$. The supernatants were separated and used for enzyme activities assays and protein determination.

\subsection{Antioxidant Enzyme Activities}

The activity of SOD was determined using the method described by Winterbourn, based on the ability of SOD to inhibit the reduction of nitroblue tetrazolium by superoxide [14]. CAT activity in tissue homogenates was measured spectrophotometrically at $240 \mathrm{~nm}$ by calculating the rate of degradation of $\mathrm{H}_{2} \mathrm{O}_{2}$ as the substrate of the enzyme using the method of Aebi [15]. GST activity was assayed by monitoring the formation of the thioether product of the reaction between GSH and 1-chloro-2, 4-dinitrobenzene at $340 \mathrm{~nm}[16]$.

\subsection{Serum Biochemical Parameters}

Cytotoxicity was determined through the leakage of the enzyme lactate dehydrogenase (LDH) in serum and tissues using commercial kits from Parsazmun Company (Tehran-Iran). Activities of aspartate transaminase (AST), alanine transaminase (ALT), alkaline phosphatase (ALP), and $\gamma$-glutamyl transferase (GGT) and levels of urea, uric acid and creatinine were determined in serum using Parsazmun Company kits (Tehran-Iran).

\subsection{Determination of GSH and MDA Levels}

GSH level was measured using the method of Tietz [17]. The end product of lipid peroxidation was estimated by measuring the level of MDA according to the method of Satoh [18].

\subsection{Protein Assay}

Protein concentration was estimated according to the method of Bradford [19] using bovine serum albumin (BSA) as a standard. 


\subsection{Statistical Analysis}

All calculations were performed using INSTAT statistical software version 3.3. All the statistical analyses were performed using one-way analysis of variance (ANOVA) with post hoc Tukey multiple comparison tests applied across treatment groups for each tissue. Significance level was based on $\mathrm{P}<0.05$. Results are expressed as mean \pm SD of six different rats.

\section{Results}

The effect of different doses of DZN on body weight and serum biochemical parameters of control and experimental groups in both rat strains after 24 hours is summarized in Tables 1 and 2.

There was a significant decrease in the body weight of Wistar rats intoxicated with DZN (> $50 \mathrm{mg} / \mathrm{kg}$ ) compared with control animals. DZN at higher doses significantly increased the activities of serum AST, ALT, ALP, GGT and LDH and levels of urea, uric acid and creatinine in Wistar rat and ALP, GGT and LDH activities and urea and uric acid levels in Norway rat compared with those of the control group.

Figure 1 shows the alteration of liver and kidney SOD and CAT activities in control and DZN-treated Wistar and Norway rats. DZN (> $50 \mathrm{mg} / \mathrm{kg}$ ) significantly increased kidney SOD and CAT activities in both rat strains compared with the control. DZN significantly increased liver SOD activity in both rat strains and CAT activity in Norway rat, while it decreased CAT activity in Wistar rat compared with the control. The increased SOD activity in Wistar rat at 200 $\mathrm{mg} / \mathrm{kg}$ DZN was significantly higher than Norway rat $(\mathrm{P}<$ 0.01). In addition, the increased CAT activity in kidney of Wistar rats was observed at 100 and $200 \mathrm{mg} / \mathrm{kg}$ DZN liver compared with the liver $(\mathrm{P}<0.001)$.

In Figure 2, the effect of various doses of DZN on GST and LDH activities in liver and kidney of both rat strains after 24 hours is given. DZN (> $50 \mathrm{mg} / \mathrm{kg}$ ) increased the activity of GST in kidney of Wistar rat and both tissues of Norway rats compared with the control. The increased GST activity was also observed at doses higher than $25 \mathrm{mg} / \mathrm{kg}$ DZN in liver of Wistar rat. The increased LDH activity was observed at doses higher than $50 \mathrm{mg} / \mathrm{kg}$ DZN in liver of Wistar and Norway rats and kidney of Wistar rats. Kidney LDH activity was significantly increased at $200 \mathrm{mg} / \mathrm{kg}$ dose of DZN in Norway rat comparing with the control.

The effect of various doses of DZN on liver and kidney GSH and MDA levels in both rat strains is depicted in Table 3. MDA level was increased as $37.86 \%$ and $48.04 \%$ in liver and $32.41 \%$ and $40.88 \%$ in kidney of Wistar rat and $25.39 \%$ and $33.81 \%$ in liver and $22.83 \%$ and $30.64 \%$ in kidney of Norway rat after DZN doses of 100 and $200 \mathrm{mg} / \mathrm{kg}$, respectively at 24 hours post-treatment in comparison to control group. GSH level was decreased as $25.37 \%$ and $34.18 \%$ in liver and $19.29 \%$ and $26.55 \%$ in kidney of Wistar rat and $15.33 \%$ and $22.45 \%$ in liver and $12.66 \%$ and $19.46 \%$ in kidney of Norway rat at 100 and $200 \mathrm{mg} / \mathrm{kg}$ doses of DZN, respectively, compared with the control.

\section{Discussion}

In this study, at higher doses of DZN, SOD, GST and LDH activities and GSH and MDA levels in liver and kidney of Wistar rats were higher than Norway rats. At these concentrations, DZN increased some serum biochemical indices such as liver enzymes activities and levels of urea, uric acid and creatinine in Wistar rat. In addition, the weights of Wistar rats treated with DZN (> $50 \mathrm{mg} / \mathrm{kg}$ ) were reduced after 24 hours exposure. This could be due to decreased water and food intake in these animals. OP insecticides cause reduction of body weight in experimental animals $[1,11,20]$. Hariri et al. [20] suggested that the weight reduction in DZN-treated rats is a result of choline esterase inhibition.

Some OPs induce the production of ROS and oxidative stress, which is associated with a depletion of GSH, alteration of antioxidant enzyme activities and increased lipid peroxidation $[1,3-5]$. There are several antioxidant enzymes in cells that prevent ROS formation and oxidative stress induction and to limit their damaging effects. SOD is the first line of defense against superoxide anion radicals, which converts it into $\mathrm{H}_{2} \mathrm{O}_{2} \cdot \mathrm{H}_{2} \mathrm{O}_{2}$ is converted into $\mathrm{H}_{2} \mathrm{O}$ through CAT [21]. In present study, DZN significantly increased liver and kidney SOD and CAT activities in both rat strains. The increased SOD and decreased CAT activities in Wistar rat were higher than Norway rat at $200 \mathrm{mg} / \mathrm{kg}$. In addition, the increased CAT activity in kidney at 100 and $200 \mathrm{mg} / \mathrm{kg}$ DZN was significantly higher than liver. The increased of these enzyme activities are probably a response to neutralize the impact of increased ROS generation in tissues. These findings are in agreement with the results of the previous reports that showed SOD and CAT activities were increased in fish liver [22] and rat heart and brain after exposure to DZN [11]. Other studies have also showed that DZN increased SOD activity no change in CAT activity in rat brain [23] and in fish gill, kidney and muscle [24]. Our result is in contrast with the findings of Shah and Iqbal [4] that showed treatment of rats with DZN orally $(10-30 \mathrm{mg} / \mathrm{kg}$ daily for 8 weeks) decreases the activities of renal antioxidant enzymes. In addition, Abdou and El Mzoudy study [3] has demonstrated that DZN administered orally to rat induced significant decreases in the activity of SOD. In this study, the decreased CAT activity in liver of Wistar rat was observed at 100 and $200 \mathrm{mg} / \mathrm{kg}$ DZN. The depletion of CAT 
Table 1. Effects of Various Doses of Diazinon (DZN) on Weight and Serum Biochemical Parameters in Wistar and Norway Rats 24 Hours Post Exposure ${ }^{\mathrm{a}}$

\begin{tabular}{|c|c|c|c|c|}
\hline \multirow[t]{2}{*}{ DZN, mg/kg } & \multirow[t]{2}{*}{ Weight, $g$} & \multicolumn{3}{|c|}{ Parameters, mg/ml } \\
\hline & & Urea & Uric acid & Creatinine \\
\hline \multicolumn{5}{|l|}{ Wistar rat } \\
\hline Control & $197.98 \pm 5.41$ & $34.47 \pm 4.97$ & $2.23 \pm 0.46$ & $0.37 \pm 0.05$ \\
\hline 25 & $195.25 \pm 7.26$ & $36.91 \pm 3.88$ & $2.68 \pm 0.51$ & $0.39 \pm 0.06$ \\
\hline 50 & $190.65 \pm 9.65$ & $39.56 \pm 5.11$ & $2.95 \pm 0.47$ & $0.45 \pm 0.06$ \\
\hline 100 & $182.06 \pm 6.36^{\mathrm{b}}$ & $42.83 \pm 3.09^{\mathrm{b}}$ & $3.43 \pm 0.38^{\mathrm{b}}$ & $0.049 \pm 0.08^{c}$ \\
\hline 200 & $177.67 \pm 12.52^{\mathrm{c}, \mathrm{e}}$ & $44.05 \pm 4.06^{\mathrm{c}}$ & $3.69 \pm 0^{\mathrm{d}, \mathrm{e}}$ & $0.54 \pm 0.08^{\mathrm{c}, \mathrm{e}}$ \\
\hline \multicolumn{5}{|l|}{ Norway rat } \\
\hline Control & $196.26 \pm 6.41$ & $29.43 \pm 3.49$ & $2.33 \pm 0.45$ & $0.42 \pm 0.04$ \\
\hline 25 & $194.26 \pm 8.26$ & $32.05 \pm 4.09$ & $2.83 \pm 0.59$ & $0.43 \pm 0.04$ \\
\hline 50 & $193.26 \pm 8.65$ & $35.22 \pm 4.24$ & $3.07 \pm 0.45$ & $0.44 \pm 0.06$ \\
\hline 100 & $189.78 \pm 7.36$ & $37.23 \pm 3.55^{\mathrm{b}}$ & $3.21 \pm 0.45^{\mathrm{b}}$ & $0.47 \pm 0.07$ \\
\hline 200 & $185.65 \pm 10.52$ & $39.38 \pm 5.34^{c}$ & $3.37 \pm 0.35^{c}$ & $0.48 \pm 0.05$ \\
\hline \multicolumn{5}{|c|}{$\begin{array}{l}{ }^{a} \text { Values are expressed as mean } \pm S D(n=6) \\
{ }^{b} P<0.05 . \\
{ }^{c} P<0.01 \\
{ }^{d} P<0.001 \text { vs. control. } \\
{ }^{e} P<0.05 \text { vs. lower doses of DZN in the same of rat strain. }\end{array}$} \\
\hline
\end{tabular}

Table 2. Effects of Various Doses of Diazinon (DZN) on Serum Enzyme Activities in Wistar and Norway Rats 24 Hours Post Exposure ${ }^{a}$

\begin{tabular}{|c|c|c|c|c|c|}
\hline \multirow[t]{2}{*}{ DZN, mg/kg } & \multicolumn{5}{|c|}{ Enzyme Activity, U/L } \\
\hline & ALT & AST & ALP & GGT & LDH \\
\hline \multicolumn{6}{|l|}{ Wistar rat } \\
\hline Control & $20.833 \pm 5.31$ & $31.33 \pm 6.51$ & $197.51 \pm 35.54$ & $33.69 \pm 5.67$ & $149.83 \pm 21.55$ \\
\hline 25 & $22.51 \pm 5.39$ & $33.17 \pm 7.01$ & $234.01 \pm 52.45$ & $36.79 \pm 4.41$ & $174.67 \pm 34.84$ \\
\hline 50 & $26.32 \pm 7.17$ & $35.16 \pm 6.68$ & $297.77 \pm 47.01^{\mathrm{b}}$ & $38.98 \pm 3.02$ & $194.83 \pm 30.83$ \\
\hline 100 & $31.46 \pm 5.29^{\mathrm{b}}$ & $36.08 \pm 6.17$ & $332.32 \pm 38.43^{\mathrm{c}, \mathrm{e}}$ & $42.32 \pm 5.67^{\mathrm{b}}$ & $215.51 \pm 23.21^{\mathrm{c}}$ \\
\hline 200 & $32.78 \pm 6.12^{\mathrm{b}}$ & $44.33 \pm 10.07^{\mathrm{b}, \mathrm{e}}$ & $377.29 \pm 87.81^{\mathrm{d}, \mathrm{e}}$ & $44.56 \pm 5.57^{c}$ & $227.51 \pm 28.39^{\mathrm{d}, e}$ \\
\hline \multicolumn{6}{|l|}{ Norway rat } \\
\hline Control & $28.67 \pm 4.27$ & $38.66 \pm 4.97$ & $196.19 \pm 42.09$ & $29.56 \pm 3.99$ & $158.17 \pm 23.39$ \\
\hline 25 & $31.51 \pm 5.58$ & $39.67 \pm 6.53$ & $226.79 \pm 45.71$ & $30.65 \pm 5.42$ & $172.33 \pm 27.98$ \\
\hline 50 & $34.17 \pm 4.45$ & $42.51 \pm 5.89$ & $264.94 \pm 29.69$ & $33.37 \pm 4.84$ & $186.82 \pm 24.85$ \\
\hline 100 & $36.17 \pm 6.31$ & $44.17 \pm 5.67$ & $304.21 \pm 43.79^{\mathrm{c}, \mathrm{e}}$ & $35.41 \pm 5.75$ & $201.67 \pm 28.12$ \\
\hline 200 & $37.01 \pm 4.77$ & $48.01 \pm 7.95$ & $346.69 \pm 58.09^{\mathrm{d}, \mathrm{e}}$ & $38.15 \pm 3.41^{c}$ & $225.17 \pm 27.18^{\mathrm{c}, \mathrm{e}}$ \\
\hline
\end{tabular}

${ }^{\mathrm{a}}$ Values are expressed as mean \pm SD. $(\mathrm{n}=6)$.

${ }^{\mathrm{b}} \mathrm{P}<0.05$.

${ }^{\mathrm{c}} \mathrm{P}<0.01$.

${ }^{\mathrm{d}} \mathrm{P}<0.001$ vs. control.

${ }^{\mathrm{e}} \mathrm{P}<0.05$ vs. lower doses of DZN in the same of rat strain

activity leads to accumulation of $\mathrm{H}_{2} \mathrm{O}_{2}$, which may be the cause of the induction of oxidative stress [25].

GST detoxicates a variety of electrophilic compounds to less toxic forms by conjugation with the thiol group of GSH and also plays an important role in protecting tissue from oxidative stress $[4,5]$. In present study, the liver and 
A

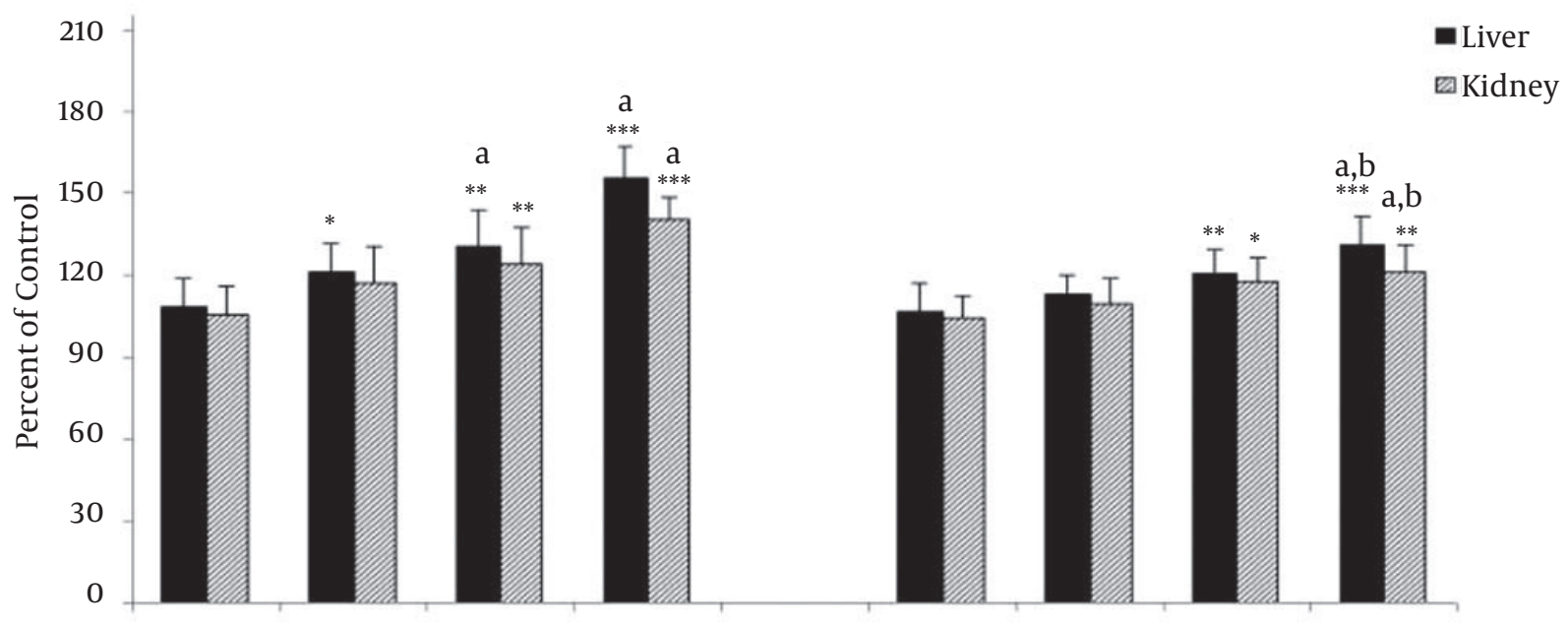

B

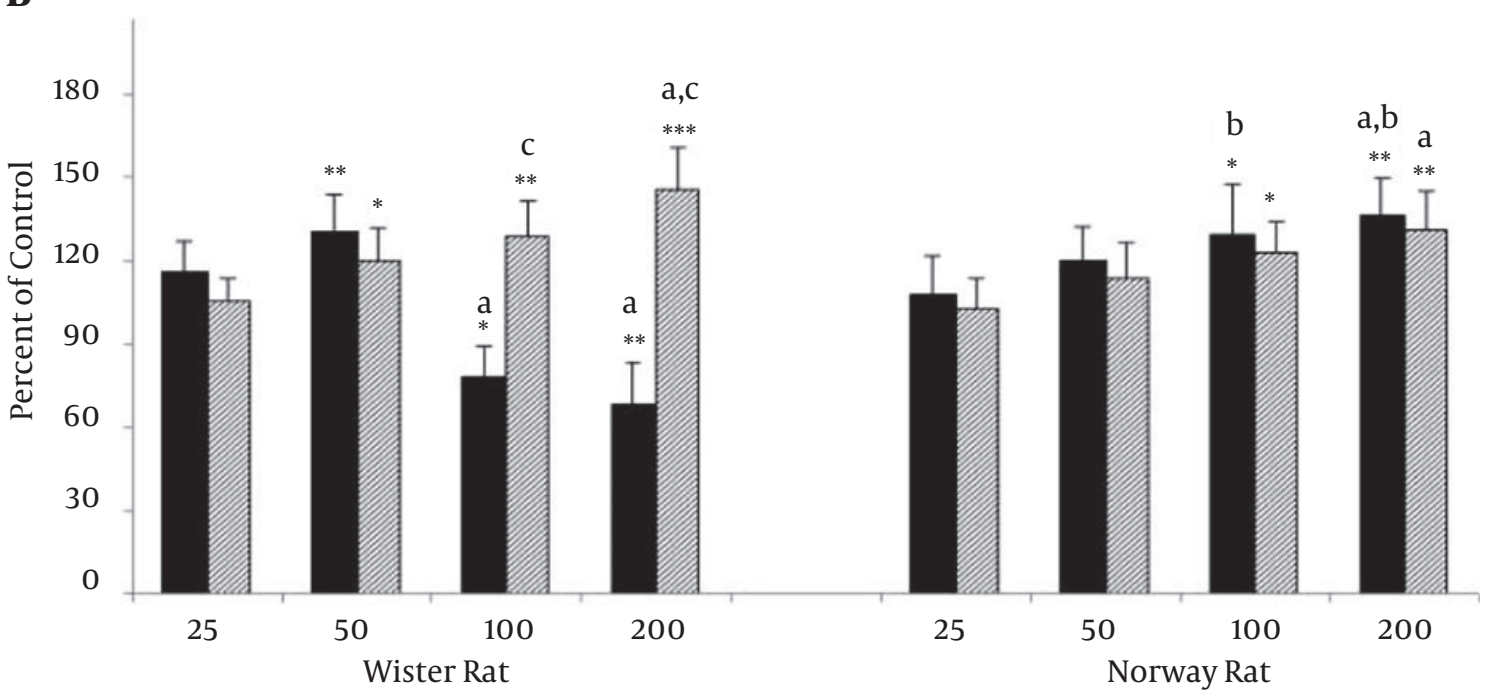

Diazinon, $\mathrm{mg} / \mathrm{kg}$

Values are expressed as means $\pm \mathrm{SD}(\mathrm{n}=6) .{ }^{*} \mathrm{P}<0.05,{ }^{* *} \mathrm{P}<0.01$ and ${ }^{* * *} \mathrm{P}<0.001$ vs. control. ${ }^{\mathrm{a}} \mathrm{P}<0.05$ vs. lower doses of DZN in the same of rat strain. ${ }^{\mathrm{b}} \mathrm{P}<0.05 \mathrm{vs}$ the same dose of DZN in Wistar rat. ${ }^{c} \mathrm{P}<0.05$ vs the same dose of DZN in liver.

kidney GST activity were significantly increased at higher doses of DZN. Elevated GST activity may reflect the possibility of better protection against pesticide toxicity $[1,11]$. The increased GST activity following exposure to DZN in various tissues of fish has been reported previously [11, 13, 22]. In addition, GST activity was not significantly affected after exposure to some OPs $[21,26]$.

GSH as an important antioxidant plays a unique role in the cellular defense systems against toxic chemicals of endogenous and exogenous source. In addition, GSH acts as an essential cofactor for antioxidant enzymes including the GSH peroxidases and GST [11]. A significant depletion of GSH was noted in the present study in concentration dependent manner in both tissues of both rat strains (Table 3). The decrease in GSH levels could be due to the presence of free radicals produced by DZN and the increased activi- 
Figure 2. Glutathione S-Transferase (A) and Lactate Dehydrogenase (B) Activities in Liver and Kidney of Wistar and Norway Rats Treated With Various Doses of Diazinon (DZN) After 24 Hours

A
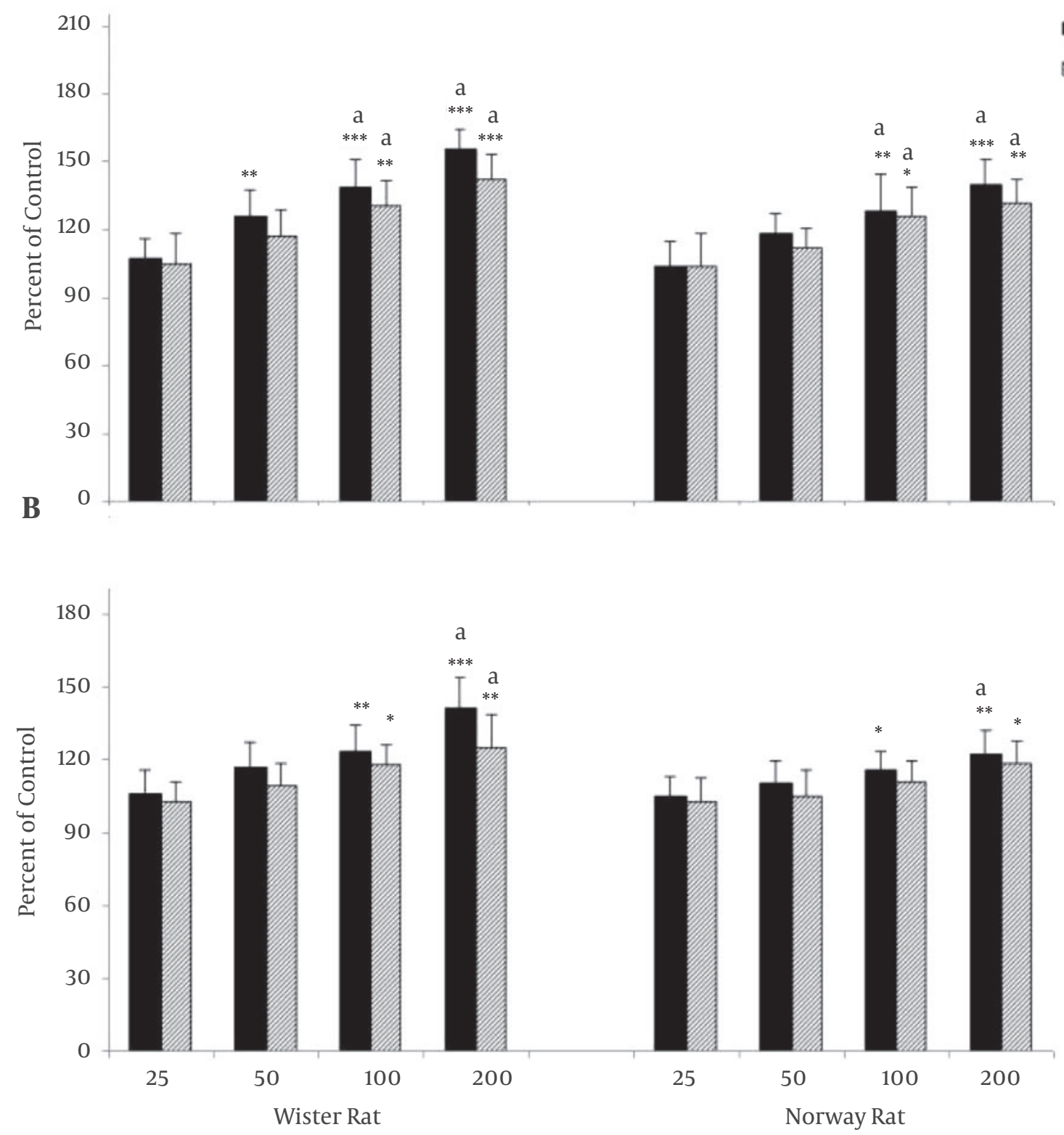

Diazinon, $\mathrm{mg} / \mathrm{kg}$

Values are expressed as means $\pm S D(n=6) .{ }^{*} \mathrm{P}<0.05,{ }^{* *} \mathrm{P}<0.01$ and ${ }^{* * *} \mathrm{P}<0.001$ vs. control. ${ }^{\mathrm{a}} \mathrm{P}<0.05$ vs. lower doses of DZN in the same of rat strain.

ties of GST enzyme [4]. Depletion of GSH leads to produce oxidized GSH (GSSG) and finally decreased the GSH/GSSG ratio in tissues of pesticides exposed rats, which is an index of tissue oxidative stress $[1,4]$. GSH is synthesized in
- Liver

ø. Kidney 
Table 3. Effects of Various Doses of Diazinon (DZN) on Glutathione (GSH) and Malondialdehyde (MDA) Levels in Liver and Kidney of Wistar and Norway Rats at 24 Hours Post Exposure $^{\mathrm{a}}$

\begin{tabular}{|c|c|c|c|c|}
\hline \multirow[t]{2}{*}{ DZN, mg/kg } & \multicolumn{2}{|c|}{ GSH, nmol/mg Protein } & \multicolumn{2}{|c|}{ MDA, nmol/mg Protein } \\
\hline & Liver & Kidney & Liver & Kidney \\
\hline \multicolumn{5}{|l|}{ Wistar rat } \\
\hline Control & $103.66 \pm 9.58$ & $38.44 \pm 4.59$ & $6.44 \pm 1.19$ & $10.34 \pm 1.67$ \\
\hline 25 & $98.43 \pm 7.56$ & $36.52 \pm 3.67$ & $7.33 \pm 0.94$ & $11.19 \pm 1.57$ \\
\hline 50 & $89.03 \pm 6.23^{b}$ & $33.57 \pm 3.91^{\mathrm{b}}$ & $8.33 \pm 0.77^{b}$ & $12.08 \pm 1.32$ \\
\hline 100 & $77.26 \pm 7.31^{c}$ & $31.076 \pm 2.43^{\mathrm{c}}$ & $8.88 \pm 0.88^{\mathrm{b}}$ & $13.69 \pm 1.97^{\mathrm{b}}$ \\
\hline 200 & $68.27 \pm 6.81^{\mathrm{d}}$ & $28.739 \pm 2.84^{d}$ & $9.54 \pm 0.78^{\mathrm{d}, \mathrm{e}}$ & $14.57 \pm 1.96^{\mathrm{c}, \mathrm{e}}$ \\
\hline \multicolumn{5}{|l|}{ Norway rat } \\
\hline Control & $93.32 \pm 7.73$ & $34.33 \pm 2.75$ & $6.11 \pm 0.97$ & $9.92 \pm 1.58$ \\
\hline 25 & $91.06 \pm 5.23$ & $33.72 \pm 3.86$ & $6.73 \pm 0.87$ & $10.59 \pm 1.04$ \\
\hline 50 & $85.31 \pm 7.42$ & $31.84 \pm 3.27$ & $7.28 \pm 0.83$ & $11.06 \pm 1.47$ \\
\hline 100 & $79.02 \pm 6.01^{\mathrm{c}}$ & $29.95 \pm 3.63^{\mathrm{b}}$ & $7.65 \pm 0.79^{\mathrm{b}}$ & $12.18 \pm 1.38$ \\
\hline 200 & $72.25 \pm 5.68^{\mathrm{d}}$ & $27.71 \pm 2.53^{c}$ & $8.16 \pm 0.72^{\mathrm{c}, \mathrm{e}}$ & $12.95 \pm 1.35^{\mathrm{c}, \mathrm{e}}$ \\
\hline $\begin{array}{l}{ }^{\mathrm{a}} \text { Values are exp } \\
{ }^{\mathrm{b}} \mathrm{P}<0.05 . \\
{ }^{\mathrm{c}} \mathrm{P}<0.01 . \\
{ }^{\mathrm{d}} \mathrm{P}<0.001 \text { vs. } \\
{ }^{\mathrm{e}} \mathrm{P}<0.05 \text { vs. lo }\end{array}$ & rat strain. & & & \\
\hline
\end{tabular}

cells defense against the toxic actions of ROS may lead to oxidative stress and cytotoxicity [1]. Our result is in agreement with the results reported by previous studies that have shown the effect of DZN on GSH level $[4,6,11]$. Depletion of GSH and the decrease in the GSH/GSSG ratio may shift cells through different biological stages, such as proliferation, differentiation, apoptosis and necrosis [4].

Lipid peroxidation is the process of oxidative degradation of polyunsaturated fatty acids, which causes impaired membrane function and structural integrity [4]. The present study showed that MDA content as an important indicator of lipid peroxidation was significantly increased in liver and kidney at high doses of DZN in both rat strains. DZN exposure caused highest accumulation of MDA in liver of Wistar rat (Table 3). The enhanced lipid peroxidation shows that DZN-induced ROS are not totally scavenged by the antioxidant enzymes. These findings are in agreement with the results of other studies that showed oral administration of DZN caused increase of MDA level in kidney, brain, heart and muscle of rat $[4,11,23]$.

Lipid peroxidation of membrane leads to the leakage of cytoplasmic enzymes, such as lactate dehydrogenase. Increases in the release of LDH have been reported to occur as a result of injury and chemical poisoning [27]. LDH activity indicates the switching over of anaerobic glycolysis to aerobic respiration [28]. According to our studies, LDH ac- tivity was significantly increased in liver and kidney of Wistar and Norway rats only at higher doses of DZN. Increase in the release of LDH in Wistar rat was higher than Norway rat. These results demonstrate a positive correlation between LDH activity and MDA level in the DZN-treated animals, suggesting that the release of LDH was a result of damage to the cell membranes due to lipid peroxidation $[3,27]$. Several reports revealed a decreased LDH activity in tissues under various pesticide toxicity conditions $[1,29]$. The increased LDH activity in serum, brain and liver was observed after rat was exposed to the pesticides [3, 12, 28].

The measurements of the activity of ALT, AST, ALP, LDH and GGT enzymes are used routinely as an indicator of hepatic dysfunction and damage $[30,31]$. These enzymes are principally localized in the cytoplasm and they secreted into the blood after hepatocellular injury, thereby increasing their levels in the serum [31]. In this study, ALP, ALT, AST, GGT and LDH activities in Wistar rats and ALP, GGT and LDH activities in Norway rats were increased at higher doses of DZN compared with those of the control group. The activities of these enzymes in Wistar rat were higher than Norway rat. These changes may have occurred due to liver dysfunction and disturbance in the biosynthesis of these enzymes with alteration in the permeability of liver membrane $[28,31]$. Several studies have reported that DZN caused degeneration in hepatocytes and changes of liver 
enzymes such as ALT, AST, and ALP and lipid metabolism [12, 32]. Banaee et al. [33] have reported increased levels of AST and ALT followed by the exposure of rainbow trout to DZN. Urea, uric acid and creatinine levels are kidney function parameters. Pesticides can alter plasma urea, uric acid and creatinine levels [1,33-35]. In this study, DZN at higher doses increased the urea, uric acid and creatinine levels in Wistar rats and the urea and uric acid levels in Norway rat. This increase may be due to kidney damage caused by DZN. Uric acid, the end product of purine catabolism, can reduce oxidative stress by scavenging various ROS [34]. The elevated serum uric acid levels may reflect a compensatory mechanism counteracting the increased oxidative stress associated with both rat strains [35].

The increased MDA and depleted GSH levels in DZNtreated rat, in the present study, is higher in liver. Liver is a major site for metabolism of exogenous chemicals such as pesticides, resulting in the formation of metabolites which may be more or less toxic than the parent compound [36]. The observed differences in DZN exposure induced responses among various tissues may depend on several factors such as oxygen consumption, metabolic activity rate, susceptibility to oxidants and many more $[1,11]$. In addition, Norway rats are more resistant to DZN toxicity, which can due to continuous contact with poisonous material in environment. The response of antioxidant system to oxidative stress shows differences from one strain to another due to DZN detoxification capacity and the differences in antioxidant potential $[9,37]$.

OPs induce apoptosis (physiological cell death) and necrosis (pathological cell death) in various tissues. The dominant form of cell death is dose-dependent. However, at conditions of higher stress, depletion of ATP and increases in the release of LDH, the cellular impairment is so high that apoptosis is suppressed. This leads to cell death by necrosis, which causes further tissue damage $[1,12,38]$. Understanding the causes of the change in the mode of cell death from one dominated by apoptosis to one in which there is significant necrosis is essential for understanding the mechanism of OPs tissue injury. Our results suggest that at lower doses ( $<100 \mathrm{mg} / \mathrm{kg}$ ), DZN induces apoptosis in tissues, whereas it induces necrosis at higher doses. However, further studies are required to determine the effects of DZN on induction of cell death in variety of cell types using an in vivo system.

Our findings suggest that DZN at higher doses induces free radical production and oxidative stress in a dose- dependent manner, as evidenced by depletion of GSH, alteration of antioxidant enzyme activities and enhanced lipid peroxidation. Norway rats are more resistant to DZN toxicity and finally antioxidant defense system is affected less. In addition, the liver is found to be more sensitive to the effects of DZN on oxidative stress induction.

\section{Acknowledgments}

The authors would like to thank Javad Rasouli and Hoosen Mahdavi for their assistance. This work was supported by a grant from chemical injuries research center and neuroscience research center of Baqiyatallah University of Medical Sciences. This research article is taken from the research code 238 written up by Dr Mahvash Jafari.

\section{Footnotes}

Authors' Contribution: Mahvash Jafari and Alireza Asgari provided design of the study and revised the article. Other authors participated in data collection and analysis. Funding/Support: Baqiyatallah University of Medical Sciences.

\section{References}

1. Jafari M, Salehi M, Asgari A, Ahmadi S, Abbasnezhad M, Hajihoosani R, et al. Effects of paraoxon on serum biochemical parameters and oxidative stress induction in various tissues of Wistar and Norway rats. Environ Toxicol Pharmacol. 2012;34(3):876-87. doi: 10.1016/j.etap.2012.08.011.

2. Mhadhbi L, Boumaiza M. Toxic Effects of Acute Exposure of Diazinon in turbot (Psetta maxima) Early Life Stage (ELS). Int J Environ Res. 2011;6(1):139-44.

3. Abdou HM, El Mzoudy RH. Oxidative damage, hyperlipidemia and histological alterations of cardiac and skeletal muscles induced by different doses of diazinon in female rats. JHazard Mater. 2010;182(1):2738.

4. Shah MD, Iqbal M. Diazinon-induced oxidative stress and renal dysfunction in rats. Food Chem Toxicol. 2010;48(12):3345-53. doi: 10.1016/j.fct.2010.09.003.

5. Lukaszewicz-Hussain A. Role of oxidative stress in organophosphate insecticide toxicity-Short review. Pest Biochem Physiol. 2010;98(2):14550. doi: 10.1016/j.pestbp.2010.07.006.

6. Marzieh R, Hosseinzadeh H, Mohsen I, Parisa L, Bibi Marjan R, Khalil A. Effect of exposure to diazinon on adult rat's brain. Toxicol Ind Health. 2013 doi: 10.1177/0748233713504806. [PubMed: 24217015].

7. Banaee M, Sureda A, Mirvagefei AR, Ahmadi K. Histopathological alterations induced by Diazinon in Rainbow Trout (Oncorhynchus mykiss). Int J Environ Res. 2013;7(3):735-44.

8. Handy RD, Abd-El Samei HA, Bayomy MFF, Mahran AM, Abdeen AM, El-Elaimy EA. Chronic diazinon exposure: pathologies of spleen, thymus, blood cells, and lymph nodes are modulated by dietary protein or lipid in the mouse. Toxicology. 2002;172(1):13-34. doi:10.1016/S0300483X(01)00575-3.

9. Oruc EO, Sevgiler Y, Uner N. Tissue-specific oxidative stress responses in fish exposed to 2,4-D and azinphosmethyl. Comp Biochem Physiol C Toxicol Pharmacol. 2004;137(1):43-51. doi: 10.1016/j.cca.2003.11.006. [PubMed: 14984703].

10. Saito K, Sakai N, Kim HS, Ishizuka M, Kazusaka A, Fujita S. Strain differences in diazepam metabolism at its three metabolic sites in spraguedawley, brown norway, dark agouti, and wistar strain rats. Drug Metab Dispos. 2004;32(9):959-65. [PubMed: 15319337]. 
11. Jafari M, Salehi M, Ahmadi S, Asgari A, Abasnezhad M, Hajigholamali $M$. The role of oxidative stress in diazinon-induced tissues toxicity in Wistar and Norway rats. Toxicol Mech Methods. 2012;22(8):638-47. doi: 10.3109/15376516.2012.716090. [PubMed: 22871176].

12. Gokcimen A, Gulle K, Demirin H, Bayram D, Kocak A, Altuntas I. Effects of diazinon at different doses on rat liver and pancreas tissues. Pest Biochem Physiol. 2007;87(2):103-8. doi:10.1016/j.pestbp.2006.06.011.

13. Isik I, Celik I. Acute effects of methyl parathion and diazinon as inducers for oxidative stress on certain biomarkers in various tissues of rainbowtrout (Oncorhynchus mykiss). Pest Biochem Physiol. 2008;92(1):38-42. doi: 10.1016/j.pestbp.2008.06.001.

14. Winterbourn CC, Hawkins RE, Brian M, Carrell RW. The estimation of red cell superoxide dismutase activity. J Lab Clin Med. 1975;85(2):33741. [PubMed: 803541].

15. Aebi H. Catalase in vitro. Methods Enzymol. 1984(105):121-6. doi: 10.1016/S0076-6879(84)05016-3.

16. Habig WH, Jakoby WB. Glutathione S-transferases (rat and human) Methods Enzymol. 1981;77:218-31. [PubMed: 6173570].

17. Tietze F. Enzymic method for quantitative determination of nanogram amounts of total and oxidized glutathione: applications to mammalian blood and other tissues. Anal Biochem. 1969;27(3):502-22. [PubMed: 4388022].

18. Satoh K. Serum lipid peroxide in cerebrovascular disorders determined by a new colorimetric method. Clin Chim Acta. 1978;90(1):37-43. [PubMed: 719890].

19. Bradford MM. A rapid and sensitive method for the quantitation of microgram quantities of protein utilizing the principle of proteindye binding. Anal Biochem. 1976;72(1-2):248-54. doi: 10.1016/00032697(76)90527-3.

20. Hariri AT, Moallem SA, Mahmoudi M, Hosseinzadeh H. The effect of crocin and safranal, constituents of saffron, against subacute ef fect of diazinon on hematological and genotoxicity indices in rats Phytomedicine. 2011;18(6):499-504. doi: 10.1016/j.phymed.2010.10.001. [PubMed: 21036580].

21. Astiz M, De Alaniz MJ, Marra CA. Antioxidant defense system in rats simultaneously intoxicated with agrochemicals. Environ Toxicol Pharmacol. 2009;28(3):465-73. doi: 10.1016/j.etap.2009.07.009.

22. Oruc E. Effects of diazinon on antioxidant defense system and lipid peroxidation in the liver of Cyprinus carpio (L.). Environ Toxicol. 2011;26(6):571-8. doi: 10.1002/tox.20573.

23. Yilmaz N, Yilmaz M, Altuntas I. Diazinon-induced brain toxicity and protection by vitamins E plus C. Toxicol Ind Health. 2012;28(1):51-7. doi 10.1177/0748233711404035. [PubMed: 21543467].

24. Durmaz H, Sevgiler Y, Uner N. Tissue-specific antioxidative and neurotoxic responses to diazinon in Oreochromis niloticus. Pest Biochem Physiol. 2006;84(3):215-26. doi: 10.1016/j.pestbp.2005.07.004.

25. Jafari M, Salehi M,Zardooz H, Rostamkhani F. Response of liver antioxidant defense system to acute and chronic physical and psychological stresses in male rats. EXCLIJ. 2014;13:161-71. [PubMed: 26417250].

26. Varo I, Navarro JC, Nunes B, Guilhermino L. Effects of dichlorvos aquaculture treatments on selected biomarkers of gilthead sea bream
(Sparus aurata L.) fingerlings. Aquaculture. 2007;266(1):87-96. doi: 10.1016/j.aquaculture.2007.02.045.

27. Banerjee A, Trueblood MB, Zhang X, Manda KR, Lobo P, Whitefield $\mathrm{PD}$, et al. N-acetylcysteineamide (NACA) prevents inflammation and oxidative stress in animals exposed to diesel engine exhaust. Toxicol Lett. 2009;187(3):187-93. doi: 10.1016/j.toxlet.2009.02.022. [PubMed: 19429263].

28. El-Demerdash FM. Lipid peroxidation, oxidative stress and acetylcholinesterase in rat brain exposed to organophosphate and pyrethroid insecticides. Food Chem Toxicol. 2011;49(6):1346-52. doi: 10.1016/j.fct.2011.03.018. [PubMed: 21419823].

29. Venkateswara Rao J. Sublethal effects of an organophosphorus insecticide (RPR-II) on biochemical parameters of tilapia, Oreochromis mossambicus. Comp Biochem Physiol C Toxicol Pharmacol. 2006;143(4):492-8. doi: 10.1016/j.cbpc.2006.05.001. [PubMed: 16765096].

30. Giron-Perez MI, Santerre A, Gonzalez-Jaime F, Casas-Solis J, Hernandez-Coronado M, Peregrina-Sandoval J, et al. Immunotoxicity and hepatic function evaluation in Nile tilapia (Oreochromis niloticus) exposed to diazinon. Fish Shellfish Immunol. 2007;23(4):760-9. doi: 10.1016/j.fsi.2007.02.004.

31. Uzunhisarcikli M, Kalender Y. Protective effects of vitamins $C$ and $\mathrm{E}$ against hepatotoxicity induced by methyl parathion in rats. Ecotoxicol Environ Saf. 2011;74(7):2112-8. doi: 10.1016/j.ecoenv.2011.07.001. [PubMed: 21782244].

32. Ogutcu A, Uzunhisarcikli M, Kalender S, Durak D, Bayrakdar F, Kalender Y. The effects of organophosphate insecticide diazinon on malondialdehyde levels and myocardial cells in rat heart tissue and protective role of vitamin E. Pest Biochem Physiol. 2006;86(2):93-8. doi: 10.1016/j.pestbp.2006.01.010.

33. Banaee M, Sureda A, Mirvaghefi AR, Ahmadi K. Effects of diazinon on biochemical parameters of blood in rainbow trout (Oncorhynchus mykiss). Pest Biochem Physiol. 2011;99(1):1-6.

34. Uzun FG, Kalender Y. Protective effect of vitamins c and e on malathion-induced nephrotoxicity in male rats. Gazi Univ J Sci. 2011;24(2):193-201.

35. El-Shenawy NS. Oxidative stress responses of rats exposed to Roundup and its active ingredient glyphosate. Environ Toxicol Pharmacol. 2009;28(3):379-85. doi: 10.1016/j.etap.2009.06.001. [PubMed: 21784030].

36. Ncibi S, Ben Othman M, Akacha A, Krifi MN, Zourgui L. Opuntia ficus indica extract protects against chlorpyrifos-induced damage on mice liver. Food Chem Toxicol. 2008;46(2):797-802. doi: 10.1016/j.fct.2007.08.047. [PubMed: 17980473].

37. Oruc EO, Usta D. Evaluation of oxidative stress responses and neurotoxicity potential of diazinon in different tissues of Cyprinus carpio. Environ Toxicol Pharmacol. 2007;23(1):48-55. doi: 10.1016/j.etap.2006.06.005. [PubMed: 21783736].

38. Li Q, Kobayashi M, Kawada T. Chlorpyrifos induces apoptosis in human $T$ cells. Toxicology. 2009;255(1):53-7. doi: 10.1016/j.tox.2008.10.003. 